\title{
Analysis of Different Types of Garment Spending By the City Dwellers with Present Context in Bangladesh: An Overview
}

\author{
${ }^{1}$ Najmul Kadir Kaikobad Rana, ${ }^{2} \mathrm{Md}$.Zafar Alam Bhuiyan, ${ }^{3}$ Farhana Sultana \\ ${ }^{I}$ Assistant Professor and Assistant Dean of Fashion Design and Technology Shanto-Mariam University of \\ Creative Technology, Dhaka; Bangladesh \\ ${ }^{2}$ Assistant Professor of Fashion Design and Assistant Proctor of Shanto-Mariam University of Creative \\ Technology, Dhaka; Bangladesh \\ ${ }^{3}$ Assistant Professor of Fashion Design, Shanto-Mariam University of Creative Technology, Dhaka, Bangladesh
}

\begin{abstract}
Bangladesh fashion history begins with history of garment industrialization in this country. How an agricultural country can be changed to a hub of garment manufacturing buy utilizing its available resources; Bangladesh is the best example for the world. There are many factors, however, which made the land suitable for the manufacturing heaven for readymade garment of the world. This hard working and modern technological industrialization is still its own based on the credit and sacrifice of the millions garment workers of the country. Fashion industry is still a new born baby in Bangladesh but it has great possibilities as we have many resources, govt. policies and demand from home and abroad for the favor of development design in this country. Fashion is one of the main concern designs which are in the take off mode in Bangladesh. Mainly city dwellers are the main consumers of fashion garments of the country. By the side by side they are also main consumers of other garments. Female from the good income level are specially very much aware of their fashion by garment where male have a significant role for the same in different condition of age, income and social strata.
\end{abstract}

Keywords: Fashion garment, Event garment, Staple garment

\section{Introduction}

From the history back, Bangladesh is a country which was known for its agriculture in the world as its land is alluvial caused different factors. Not only the productivity of agriculture is notable but also in other cases productivity (fertility is high) is high. May be there is a scientific cause being an area of tropical region and for its different types of environmental factors. Though traditionally our profession was agriculture and farming was easiest than others, most of the people used to live in villages and all the dimensions of the country were focused a country for village dominated with agriculture. Previously it was said that the country was famous for its agriculture whole over the world and it continued up to 1966, then the East Pakistan when a tailoring house could 10000 shirts exported to England for the first time. As it was a win- win situation from the both sides, new teams of the buyers started to visit the country to discover the manufacturing facility of the country with its existing capabilities of that time. But unfortunately, the time wasn't favorable for then the East Pakistan as a movement was going on for the independence of the country from Pakistani rulers. On the other hand, the rulers of the country didn't patronized for the development of this sector in that time, though some of the private organizations tried their best but failed for the ongoing country situation and lacking actual support from the government of that time. Later, after the blood bathing victory of the country, then the government of Bangladesh had taken serious initiative to reconstruct the total infrastructure development to emerge an industrial revolution. Factoring different national and international elements, the new govt. couldn't do much for the industrial revolution of the country, though it had made the effort for it best. The main countries didn't support then the policies of the govt are Saudi Arabia and its friends, China, USA, etc. As a result we couldn't draw huge investment from outside of the country as like today. The flood and famine of the country of 1974 and political unrest had created a real unstable situation of the father of the nation's govt. After a blood shedding army coup, the political scenario had changed with the reorganization of then the govt. achieved leading by the aforesaid countries.

Most importantly, after that, the growth of RMG sector produced a group of entrepreneurs with the help of the govt., who have created a strong private sector as the policy of the previous government. Most of the entrepreneurs were female. Bashakhi garment, the oldest exporting capacity garment factory was established by a woman in 1977. Many women were in the leading position of the factories. By last 35 years, there are many phenomenal changes in the garment sector especially for the hundred percent export oriented garment. There were only 9 export-oriented garment manufacturing units in 1978, when earning one million dollars was very difficult. Actually those garment produced for domestic and export market and those were very small. Four such small and old units were Reaz Garments, Paris Garments, Jewel Garments and Baishakhi Garments. 


\section{Objectives of the Study:}

-To estimate present and future demand of fashion garment to open and finally shift the country as a land for fashion garment and use present resources for the design based industrialization.

-To check the purchasing trend of the customers of Dhaka City and demand of different types of garments.

-To assess the future demand of different types of garment in the city as well as the country to fulfill the instant demand in future.

\section{Literature Review:}

Reaz Garments, the first garment factory, was established in 1960(BGMEA, 2013) as a small tailoring outfit, named Reaz Store in DHAKA. It was only for the inside market of the country and it served for 15 years. In 1973 it had changed its name as to M/s Reaz Garments Ltd. and made the development by exporting 10,000 pieces of men's shirts worth French Franc 13 million to a Paris-based firm in 1978s(Bhuiyan,2011). It was the pioneer exporter of garments from Bangladesh. Up to the late 1970s, the RMG industry started developing in Bangladesh primarily as an export-oriented industry although; the domestic market for RMG has been increasing fast due to increase in personal disposable income and change in life style. The sector rapidly attained high importance in terms of employment, foreign exchange earnings and its contribution to GDP (BGMEA, 2013).

Another garment factory Desh Garments Ltd, the first non-equity joint-venture in the garment industry was established in 1979s. It had the technical, operational and marketing collaboration with Daewoo Corporation of South Korea. It was also the first hundred percent export-oriented company of Bangladesh garment exporting history. It had about 120 operators including 3 women trained in South Korea, and with these trained workers it started its production in early 1980s (BGMEA, 2013). The first equity based South Korean Firm; Youngones Corporation formed the first equity joint-venture garment factory with a Bangladeshi firm, Trexim Ltd. in 1980s. Where, Bangladeshi partners contributed $51 \%$ of the equity of the new firm, named Youngones Bangladesh (BGMEA, 2013). It exported its first consignment of padded and non-padded jackets to Sweden in December 1980s as a successful exported batch of garment with the good reputation of the country.

Up to the end of 1982, there were only 47 garment manufacturing units. But within 1984-85, when the number of garment factories increased to 587 it was noticed by the international market that Bangladesh was growing as a manufacturing country of the world for garments products. The number of RMG factories increased up to around 2,900 in 1999. Bangladesh is now for knit garment the $2^{\text {nd }}$ largest country of the world and for the manufacturing, it is the $3^{\text {rd }}$ largest country of the world.

At present there are about 4800 garment factories in the country and 75 percent of them are in Dhaka. The rest are in Chittagong and Khulna. These factories have employed 35 lacks of people and 85 percent of them are illiterate rural women. About 77 percent of our export earning comes from this sector. After agriculture, this is the largest sector of earning of the country people. It has a huge contribution to ease the unemployment problem of the country. Directly and indirectly more than one core people are engaged in this sector (Bhuiyan, 2013).

This sector has uplifted the neglected section of the population, thus radically transforming the socio-economic condition of the country. Such empowerment and employment raised awareness regarding children education, health safety, population control, disaster management, etc. Now in Bangladesh, RMG sector is the main source of foreign earnings in Bangladesh by contributing more than 80 percent of the same.

\section{Factors Affecting Fashion In Bangladesh At Present}

Though history of country fashion is totally based on readymade garment of the country, now the scenario has changed. With the fashion fever of the world, Bangladesh also enclosed its name successfully with fashion by the following factors:

Cultural Effect: Bangladesh is a country of enriched culture in the world. It has lots of diversifications due to the living of different religions in the small tract in a harmonious combination.Though there are some small niches of culture dominated by some famous ethnic groups or tribal people, there is no division in major population of the country. Nowadays, the youngsters are very much conscious about the cultural changes in the surroundings and very easily they get involve in with the same. It is also mark able that though its starts in urbane but its huge reception is happen by the youngsters of the surroundings of the cities of Bangladesh. For example, nail painting is an ongoing trend is more popular in Gazipur (a small town near Dhaka) than that of Dhaka, though it has been started in Dhaka first in Bangladesh. On the other hand, young women of Dhaka wear tights more than that of Gazipur and once according to the last references can say that they will adopt it much of Dhaka in future.

Socioeconomic Change with time: The per capita income of Bangladesh is \$1044(Bangladesh Bank, 2014), when it was only $\$ 470$ in 2006. More income opens the more options for consumption and creates market. It is 
noticeable even a few days back people used to go for shopping for their dresses in Eid, Puja and Christmas. But now they purchase new dresses in many events like Pohela Baishakh (the first day of Bangla new year),Pohela Falgun (the first day of Spring), valentine's day, father's day, friendship day etc. Nowadays, different events of the country are more colorful than before. According to the census, 55 percent of our total population is youngsters who like to have the present trends and go with the fashionable fits and obviously there is a competition within them for that.

Globalization: Bangladesh is not a small market nowadays. It's a country of emerging tiger according to World Bank. So, as like cultural diffusion, different wings of trends are engulfing the country society so that people are going with different dresses and out looks to have the makeable space in the society. Different brands have opened their wings in Bangladesh and many local Brands are on the pipeline to fulfill the market demand for the current trends. On the other hand, local boutique houses have opened product diversifications to fulfill the demand of different types of customers. As a result, customers are buying dresses not only for the requirement according their demand, but also for the variation of colors, design, fabrication, surface decorations, fashion details and budgets.

Effect of Mass education: Mass education is the motto of present govt. of Bangladesh which ultimately plays very vital role in fashion. Mass education has played a role not in the town but also in the village to go for fashion.

Education opens the door of cultural studies, Factors changing the external environment sense of Fashion, knowledge about garment, sources. Of course for the color sense, there is a sharp difference between educated and an uneducated person in a general case.

Business Policy of the country: It is very easy to run a business with or without a bank support of the country cause we need more investment and entrepreneurship for the development of the country. Public and private investment is much higher than before.

Information Technology: Information Technology has a significant role to spread the information about present trend, fashion out looks, availability of products, prices, discounts, etc. Nowadays many organizations are doing business by online by ensuring home delivery. Using face book, LinkedIn and other media are very much common today. Now a consumer can purchase a fashion product by viewing the images and information of the product without fuel cost of transport, losing valuable time and hassle and throbbing of traffic jam.

Empowerment of Women: Now, women are more empowered than before because they are earning money and government has taken many initiatives for the development of women by education, enacting laws for the favor of women rights.

Competition amongst the different strata of the society: There is a sharp competition amongst the groups of the society. For different types of causes, individuals and social groups are in a competition. In case of elite class for explore themselves as a class of aristocracy; people are going for extraordinary styling sometimes which is outreach for other classes of the society. Sometimes to explore their fashion even almost nothing is impossible by them. They are people almost damn care of the society .Now in Bangladesh; higher class people have drawn a sharp distinct line between common people and them by adopting different types of fashion very common and normal for their daily life.

Breaking the circle of traditional Fashion: This is also done by some people who are in higher class in Bangladesh. Young generation is in leading whenever the seniors are on the tract by financing and supporting them directly or indirectly. Nowadays most of the young generation is out of bangle tradition. We can go for a vital example .There was a survey within the students of fifth semester about their favorite dress. Out of 43, students (most of female) none answer sari (a famous and the oldest classic female dress of the world) for the traditional dress of Bangladesh!

\section{Method and Methodology}

We have taken 100 consumers from the different levels of the society of Dhaka city in the random sampling basis. Out of this sample male and female numbers was 50 each for different age and for different professions.we have taken primary data from this sample with a prefixed questionnaire. The result of the questionnaire has analyzed and displayed in the statistical measures by line diagrams. 


\section{Result analysis}

For the result of the study we have set line diagram to show the statistical data analysis so that any person can easily get the information in a simplest way. In the Figure 2 we have interpret the analysis to show the consumption of different types of dresses by different age group and in the Figure 3 purchasing trend of Fashion garment by Female verses male garment users.

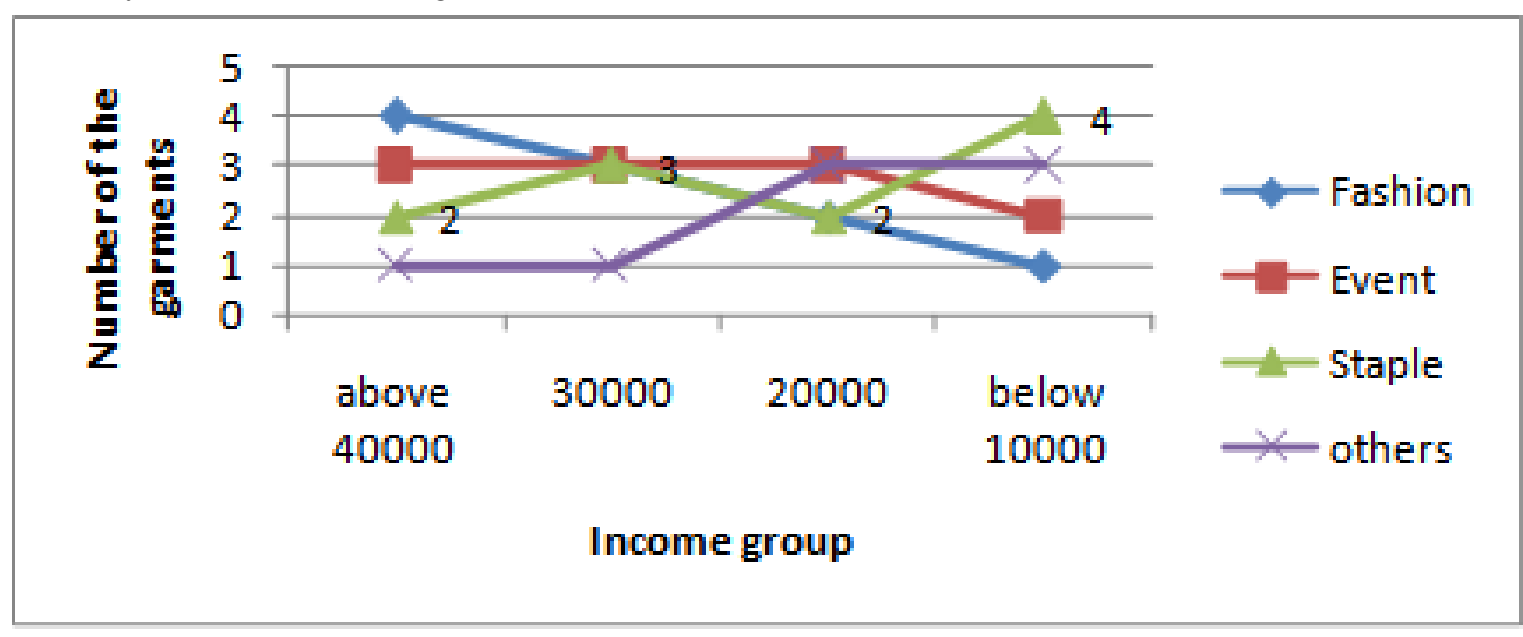

Figure 1: Purchasing trend of different garment in the Last year (out of each ten garments)

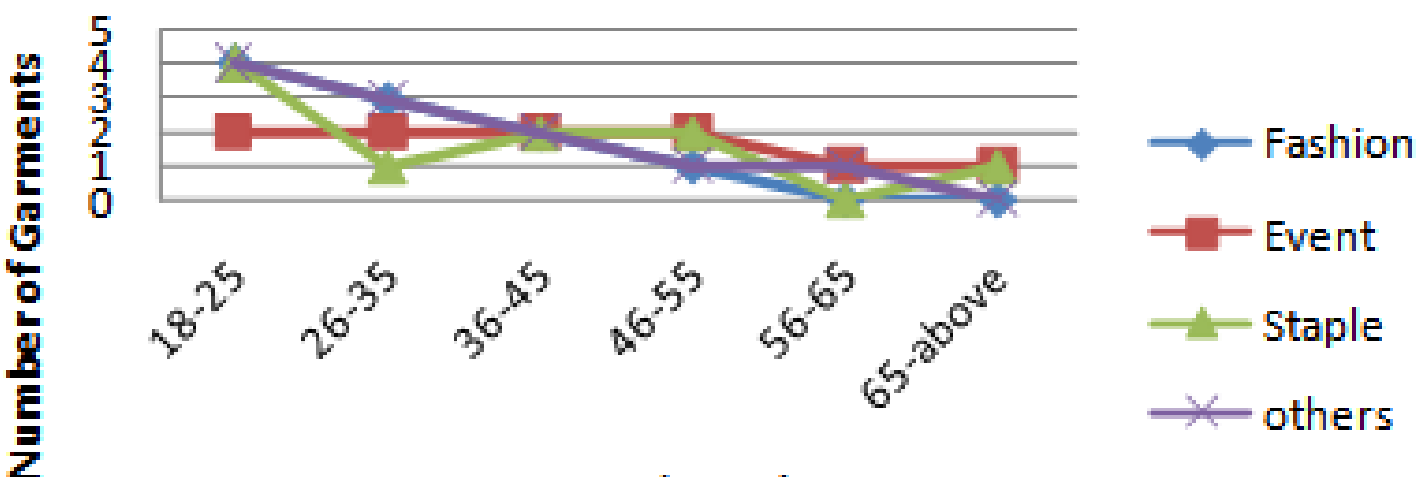

Age Group(years)

Figure 2: Purchasing of different types of dresses in different by different age group (for every ten garments)

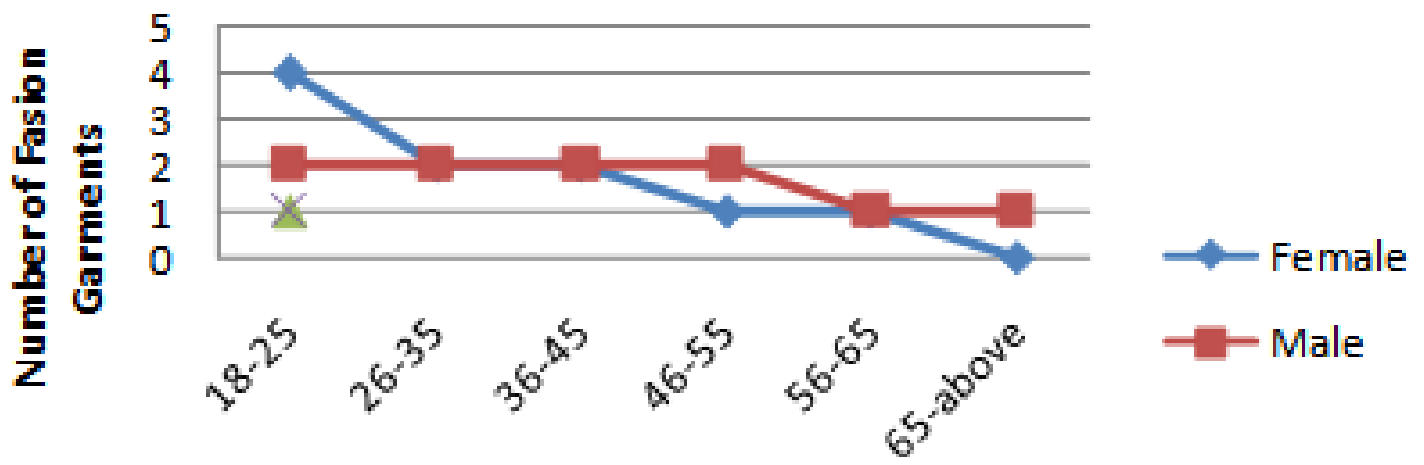

Age Group(years)

Figure 3: Purchasing trend of Fashion Garment Male verses Female 


\section{Findings:}

For the purchasing trend of fashion garment and in a declined mode from the 18-25 age groups to the upper age groups; whereas, highest percentage of staple garments is purchased by the same group. Interestingly, event garment remains same from age 18-25 to 45-55 years! Staple garment demand is least in the age group of 56$65 \mathrm{yrs}$ and it is highest in case of age group 18-25 yrs. On the other hand, event garment also least used by the age group 56-65. It's really a fun that age groups of 46-55 yrs use all types of garments in a similar quantity. Interestingly, men keep their fashion trend same from their 18-25yrs to 46-55yrs in case of fashionable garments! After 65 yrs most of the women have no interest in fashion as they didn't go for purchasing of fashion garments. There is a sharp gap regarding the use of fashion garment (Fig: 03) in the age level of 18-25yrs and 46-55 yrs respectively however, for age ranges $26-35$ to $36-45 \mathrm{yrs}$ it was parallel. Income, age and sex have direct influences of selection and purchasing garment categories and even for the number of frequency for the same types garment for the same fashion whenever, people from low income generation purchase clothing for multipurpose uses. On the other hand, staple garment demand has the great fluctuation against their (demand and) income, whereas fashion garment has a little fluctuation for the same.

\section{Conclusion:}

Bangladesh is a country of garment products. Its manufacturing process is recognized worldwide. Days are not far away that Bangladesh will able to export its design to developed other countries as industries will develop by the local and international entrepreneurship of the country. Once there will grand gala as like our neighboring country India and another door of development will be open with multiple options of earnings and development.

\section{References:}

[1]. Asiatic Society of Bangladesh (2006) “Garment Industry” in Banglapedia, Asiatic society of Bangladesh, Retrieved August 7, 2006 fromhttp://banglapedia.org/HT/G_0041.HTM

[2]. Bangladesh Garments Manufacturers And Exporters Association (BGMEA)-Government recognized trade body of the garments factories of Bangladesh, <www. bangladesh garments. Info>accessed during the period 2003-2007

[3]. Bhuiyan , Z.A.(2012),Present Status of Garment Workers of Bangladesh:An analysis,IOSR Journal of Business and Management, ISSN 2278-487X, Vol 3,Issue 5,(Sept-Oct, 2012,pp38-44)

[4]. Bhuiyan, Z.A. (2008): Marketing Prospect of Product Design and Development of Bangladesh, Seminar Paper with Net herein University, Germany.

[5]. BBS (1989) "Report on Labor Force Survey 1989", Bangladesh Bureau of Statistics, Government of Bangladesh, Dhaka

[6]. BGMEA (2007) Directory of the Bangladesh Garments Manufacturers Association 2006-07

[7]. Bhattacharya, Debapriya (2007).Bangladesh"es apparel Sector in Post -MFA period: A benchmarking study ongoing Restructuring Process, A publication by Center for Policy Dialogue (CPD)

[8]. Export promotion Bureau, Bangladesh (EPB)www.epbd.com/, accessed during January, 2014. 